\title{
The Distribution of Malaria with Seasonal in Kokap Yogyakarta 2012-2017
}

\author{
Raden A.K. Lestari ${ }^{1}$, Novyan Lusiyana ${ }^{2 *}$, and Fitria S. Nurochmah ${ }^{2}$ \\ ${ }^{1}$ Undergraduate Student, Faculty Medicine, Universitas Islam Indonesia, Yogyakarta, Indonesia \\ ${ }^{2}$ Departement of Parasitology, Faculty Medicine, Universitas Islam Indonesia, Yogyakarta, Indonesia
}

\begin{abstract}
Kokap is one of the endemic areas of malaria in Yogyakarta. The transmission of malaria was influenced by multiple factors including season. The impact of the rainfall rate in the rainy season was increasing the breeding place of vector-borne diseases, especially malaria. This study aims to describe the case of malaria, the relationship with season and mapping of endemic areas of malaria in Kokap I Primary Health Centre at Kulon Progo in 2012-2017. This is a descriptive epidemiological study with an ecological study approach. The study population was malaria cases in Kokap I Primary Health Centre. Data were analyzed descriptively and then mapped based on the endemic areas. The result showed 245 cases of malaria consisting of 136 men (55.5\%) and 109 women (44.5\%), on which 166 of them were in 15-45 years age group $(67.7 \%)$. There were $59.2 \%$ of patients were positive of $P$. vivax infection and $40 \%$ of patients were positive of P. falciparum. Malaria cases in 2012-2017 at rainy season, moist season, dry season were 109, 59 and 77 respectively. Malaria cases were increased from October to April which is the rainy season, but there is no significant difference between rainy season and dry season with the incidence of malaria $(p=0.316)$. Kalirejo village was found as a medium-high endemic village, while Hargomulyo and Hargorejo Villages were lowmedium endemic villages. During 2012-2017, we found that malaria in Kokap was dominated with P. vivax infection and the malaria incidence was increased in the rainy season.
\end{abstract}

Keywords: season, malaria, incidence, Yogyakarta.

\section{Introduction}

Malaria is a disease caused by Plasmodium sp. Malaria has still become the main parasitic diseases in the world. Malaria was transmitted by infected female Anopheles sp. mosquito by injects the sporozoites stage. Five species infect humans, Plasmodium falciparum (P. falciparum), Plasmodium vivax ( $P$. vivax), Plasmodium malariae $(P$. malariae), Plasmodium ovale (P. ovale) and Plasmodium knowlesi (P. knowlesi). Plasmodium falciparum is the most prevalent malaria parasite in South-East Asia $(62.8 \%)^{1}$. Frequent species in Indonesia are $P$. falciparum and $P$. vivax. The malaria death was associated with $P$. falciparum but occasionally by $P$. vivax.

Accounting for over 219 million cases of malaria occurred worldwide in 2017. Most malaria cases were found in the African Region (95\%) and followed by South East Asia $(5 \%)^{2}$. In Southeast Asia, Malaria incidence was decreased to 59\% from 2010 to 2017. So, malaria in South East Asian was the largest declines that occurred in the WHO region, reflecting the reduction trends in malaria incidence. Based on the Indonesian Ministry of health [3], Kulon is a district that endemic of malaria in Yogyakarta with API < 1[Annual Parasite Incidence]. The prevalence of Malaria in Kokap was fluctuating from 2011-2017. Malaria was increased in 2012 (237 cases) compared to
2011 (157 cases), declined until 2014 and increased again in 2015 [4].

The increase of malaria cases is influenced by several factors such as host, agent, and environment. Environmental factors are such as climate, rainfall, temperature, and humidity ${ }^{5}$. A study showed that rainfall and temperature increase humidity and the humidity had a significant correlation with the incidence of malaria[5]. Takayohsi [6] research showed that a high incidence of malaria was in September-February.

In this study, we evaluate the relationship of rainfall on the incidence of malaria in the Kokap Primary Health Center in Yogyakarta. This research could be used to take effective preventive strategies to control malaria di Kokap Yogyakarta.

\section{Materials and Methods}

Kulon Progo is one of four districts in Yogyakarta, which located $30 \mathrm{~km}$ from the city of Yogyakarta with an area of $586.28 \mathrm{~km}^{2}$. This district is located in lowlands and surrounded by mountains which are mostly located in the north. In the north area, which is $11.37 \%$ areas of Kulon Progo had an altitude $>500 \mathrm{~m}$ above sea level ${ }^{7}$. The range annual rainfall of this district is $0-693 \mathrm{~mm}^{3}$ and its average 
temperature ranges from $20^{\circ} \mathrm{C}-31^{\circ} \mathrm{C}$. The relative humidity is between $40-96 \%$ during the year[8].

This study had approval from the Ethic commission of Faculty of Medicine, Universitas Islam Indonesia. This research is an epidemiological study with an ecological study approach. This study was based on the medical record of malaria cases in Kokap Primary Health Center from 2012 to 2017. All malaria cases during the period were included in this research. The inclusion criteria for malaria cases were patients whose positive malaria confirmed with a peripheral blood smear. The rainfall data were obtained from the Climatology and Geophysics Meteorology station in Yogyakarta.

The characteristic of malaria cases, Plasmodium type, and rainfall rate were presented in graphical form. Statistical analysis was performed using univariate and bivariate analysis to see the malaria distribution and the endemic areas were mapped using QGIS software.

\section{Results and Discussion}

Kokap is a highland area in Yogyakarta which is called Menoreh hills. This study shows that malaria occurs at high altitude, this finding was consistent with a study performed before ${ }^{9}$. Malaria occurred all year round but predominantly in the rainy season. In Kokap, transmission peaked in October until April. The result of our study was the following another study ${ }^{6}$. The malaria incidence was associated with climate phenomenon, warm temperatures, and high precipitation[5,6,10,11]. In this condition, larval density was high and associated with puddles, farms, and drain ${ }^{10}$. The presence of standing water was dependent on rainfall, the higher rainfall supporting the breeding site of Anopheles mosquitoes. In Kokap, there are many urban farms, puddles, and trees. This kind of geographical area was suitable for the Anopheles breeding site ${ }^{10}$. Temperature and precipitation are sensitive to some species of Plasmodium and the elderly were more sensitive to the change of temperature and precipitation ${ }^{11}$.

The environmental factor that influences the breeding site of Anopheles sp. is rainfall. The malaria incidence was increased in 2014 directly proportional to the increase in the rainfall rate. This condition was in contrast in early 2017 when the rainfall rate was increased but a decrease in malaria cases. The trends of malaria and rainfall rate in Kokap can be seen in Figures 1 and 2 .

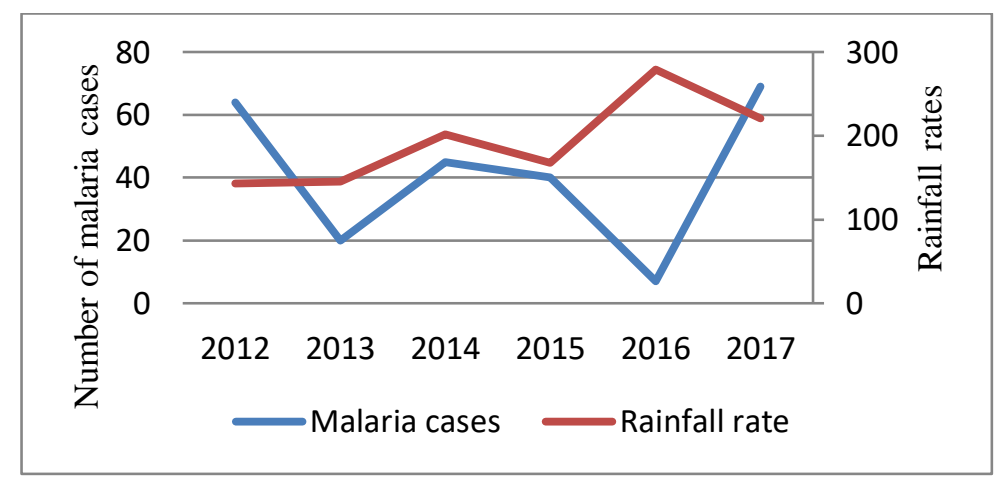

Figure 1. Distribution of malaria cases and rainfall rate in Kokap

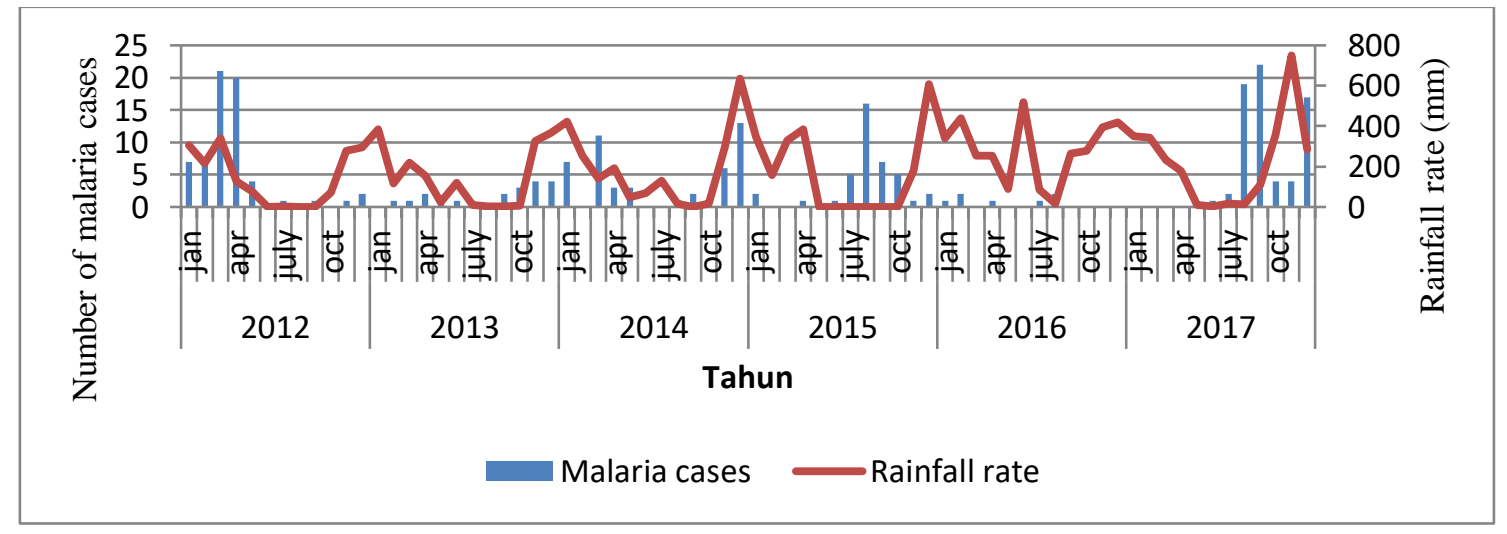

Figure 2. The distribution of malaria cases based on rainfall rate

A correlation test was performed to determine the relationship between malaria cases with seasonal. The correlation result showed $p=0.316$, which means there is no relationship between malaria cases and rainfall in Kokap (Table 1). This result was in correlation with other studies that state that malaria incidence was increased with increasing rainfall [12].
In this study, the number of malaria cases from 2012-2017 was 245 cases. The incidence of malaria fluctuated among that year. Malaria was decreased until 20 cases in 2013 which is previously 64 cases. The highest malaria incidence was in 2017 with 69 cases, whereas in the previous year malaria was very low (Table 1). 
Table 1. Malaria cases with seasonal in Kokap in 2012-2017

\begin{tabular}{lllll}
\hline \multirow{2}{*}{ Years } & \multicolumn{4}{l}{ Number of malaria cases } \\
\cline { 2 - 5 } & $\begin{array}{l}\text { Rainy } \\
\text { season }\end{array}$ & $\begin{array}{l}\text { Moist } \\
\text { season }\end{array}$ & $\begin{array}{l}\text { Dry } \\
\text { season }\end{array}$ & $p$ \\
\hline 2012 & 38 & 20 & 6 & \\
2013 & 11 & 2 & 7 & \\
2014 & 26 & 14 & 5 & 0.316 \\
2015 & 5 & 1 & 34 & \\
2016 & 4 & 0 & 3 & \\
2017 & 25 & 22 & 22 & \\
Total & 109 & 59 & 77 & \\
\hline
\end{tabular}

Malaria cases for the last 6 year has consisted of 136 $(55.5 \%)$ men and 109 (44.5\%) women (Table 2). Malaria is a disease that can infect all ages of groups. This study indicates that malaria cases are mostly suffered by men rather than women, as shown in other studies $[9,10,13]$. This result was reinforced by Kemenkes [2013], that malaria tends to be suffered by men. This can be caused by works factors, where more men were sleeping outdoor [15]. Malaria infection also dominated by productive groups $[9,10]$.

Table 2. Characteristic of malaria cases in Kokap 2012-2017

\begin{tabular}{lcccccc}
\hline \multirow{2}{*}{ Characteristics } & \multicolumn{6}{c}{ Number of malaria cases (n) } \\
\cline { 2 - 7 } & 2012 & 2013 & 2014 & 2015 & 2016 & 2017 \\
\hline Gender & 28 & 9 & 23 & 21 & 4 & 24 \\
Female & 36 & 11 & 22 & 19 & 3 & 45 \\
Male & & & & & & \\
Age (years) & 17 & 4 & 14 & 6 & 0 & 14 \\
$<15$ & 43 & 15 & 29 & 31 & 6 & 42 \\
$15-64$ & 4 & 1 & 2 & 3 & 1 & 13 \\
$>64$ & & & & & & \\
\hline
\end{tabular}

The frequency of malaria cases among the year can be seen with API. Annual Parasite Index was the number of malaria that had confirmed by microscopic blood test per 1.000 populations by year (\%o). The API level can determine the level of endemicity area. The largest API was in 2013 (3.33\%o) and the lowest was in 2016 (0.31\%o) as seen in Table 3.

Table 3. Distribution of malaria cases and API in Kokap in 2012-2017.

\begin{tabular}{llcc}
\hline Years & $\begin{array}{l}\text { Number of } \\
\text { Population }\end{array}$ & $\begin{array}{c}\text { Number of } \\
\text { malaria }\end{array}$ & API (\%o) \\
\hline 2012 & 19.232 & 64 & 3.33 \\
2013 & 21.633 & 20 & 0.92 \\
2014 & 20.675 & 45 & 2.18 \\
2015 & 21.259 & 40 & 1.88 \\
2016 & 22.342 & 7 & 0.31 \\
2017 & 22.674 & 69 & 3.04 \\
\hline
\end{tabular}

The result of this study showed that malaria in Kokap in 2012-2017 was caused by $P$. vivax and $P$. falciparum. This result was in agreement with the result of Riskesdas done by the Indonesian Health of Ministry that Plasmodium the dominant species found in Indonesia. ${ }^{14}$ Plasmodium falciparum infection was higher in 2012 (90.6\%), while P. vivax was in 2017 (97.1\%). A similar result was also stated that the dominant species that caused malaria in Indonesia was $P$. vivax[16,17].

Out of 245 malaria cases, $98(40 \%)$ were infected with $P$. falciparum and 145 (59.18\%) infected with $P$. vivax and mix $2(0.82 \%)$ cases. Malaria in 2012-2014 was mostly caused by $P$. falciparum, while 2015-2017 caused by $P$. vivax. Mixed infection of Plasmodium was found in 2015 and 2017. The distribution of malaria can be seen in Figure 3.

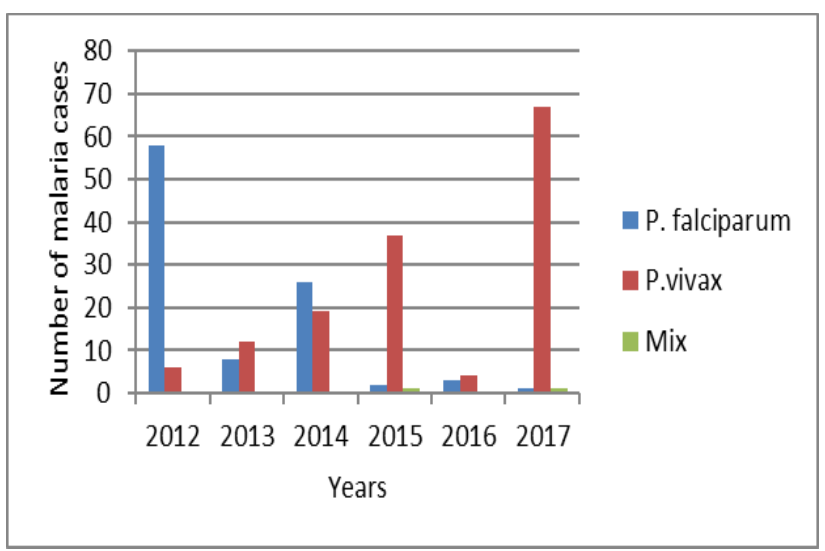

Figure 3. Distribution of malaria cases by Plasmodium species.

Kokap has three villages that are Hargomulyo, Hargorejo, and Kalirejo. The highest malaria case was found in Kalirejo village. Malaria in Hargorejo was quite stable, while in Hargomulyo are fluctuating. The distribution of malaria can be seen in Table 4 .

Table 4. Distribution of malaria cases within the village in Kokap.

\begin{tabular}{lcccccc}
\hline \multirow{2}{*}{ Village } & \multicolumn{7}{c}{ Cases (n) } \\
\cline { 2 - 7 } & 2012 & 2013 & 2014 & 2015 & 2016 & 2017 \\
\hline Hargomulyo & 1 & 3 & 28 & 0 & 0 & 6 \\
Hargorejo & 8 & 3 & 5 & 6 & 1 & 12 \\
Kalirejo & 55 & 14 & 12 & 34 & 6 & 51 \\
Total & 64 & 20 & 45 & 40 & 7 & 69 \\
\hline
\end{tabular}

The variability in the prevalence of malaria among the village is in agreement with the previous study in the highland $\operatorname{area}^{17}$. The endemicity influenced by geographical conditions such as the rice field, puddles, and drain ${ }^{10}$. The endemicity village in Kokap were divided into three groups using API. Distribution of malaria in Kokap divided into low endemic with API $<1$, moderate with API 1-5 and high endemic with API $>5$ (Table 3). The API of malaria in Kokap since 2012-2017 was $3.33 \%$, $0.92 \%$, $2.18 \%$, $1.88 \%$, $0.31 \%$, and 3.04 $\%$ respectively (Figure 4 ). 


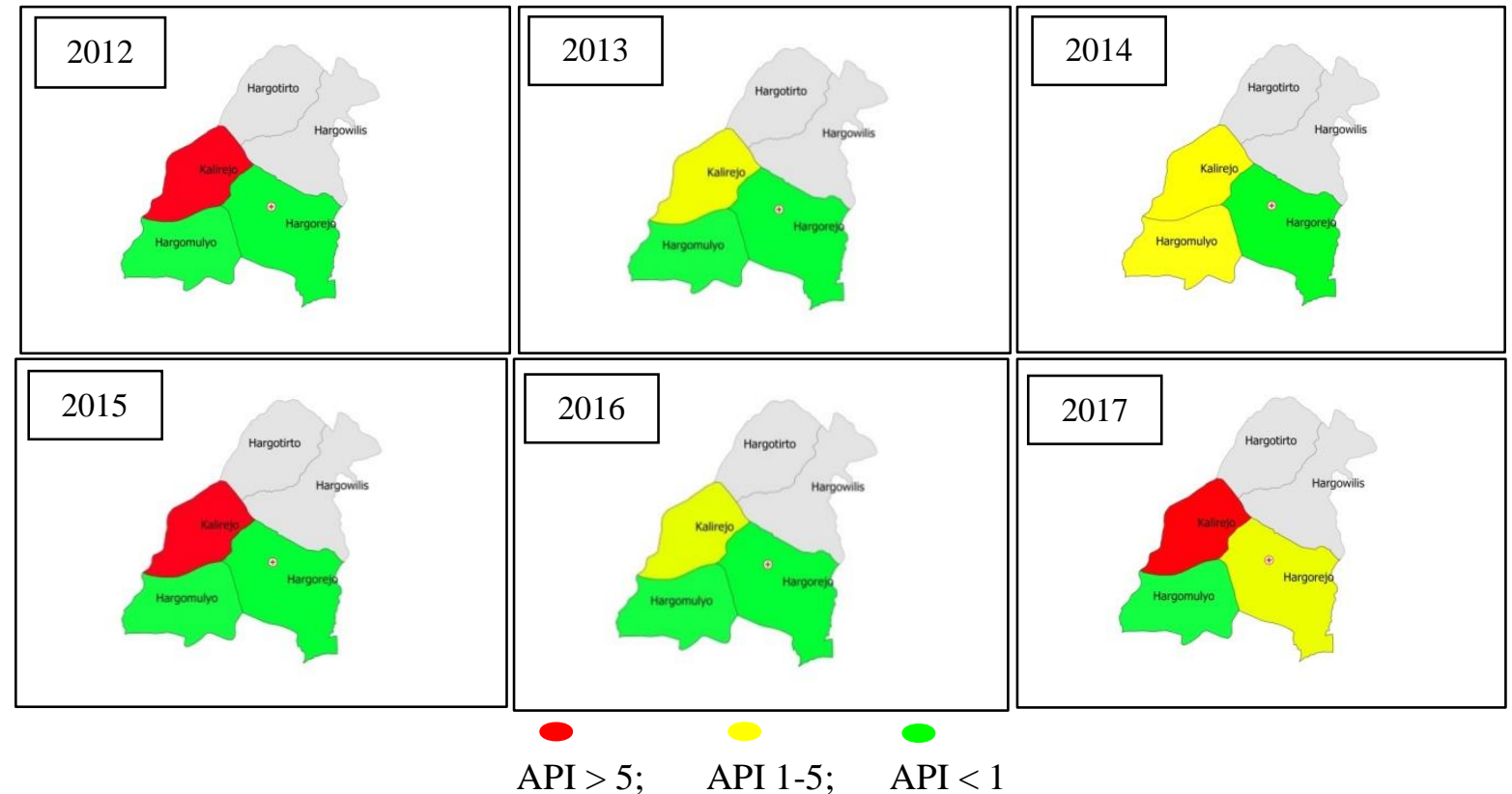

Figure 4. Mapping of the endemic village in Kokap.

Based on Kemenkes data, Kulon Progo was the low endemic area of malaria[7,14]. The high incidence of $P$. vivax infection in Kokap was caused by a newcomer from Nias islands to Kalirejo village. Blood smear of the newcomer was conceived of the gametocyte stage. Malaria incidence in low endemic malaria could be caused by an imported person from high endemic malaria or traveller [12] Gametocyte in asymptomatic and submicroscopic infection was a significant contributor to malaria transmission [18] .

Elimination of malaria in Kulon Progo already implemented a long time, but still experiencing problems. This problem caused by the decreasing number of malaria workers in villages and ineffective communication between areas with similar malaria problems [19]. Another problem is the decentralization policy [19]. But, the previous study showed that Based on the research data before, it showed that people of Kulon Progo had good basic capital support for malaria elimination such as perception of malaria, awareness, and participation [19].

\section{Conclusion}

This study showed that the most prevalent species was $P$. vivax. The incidence of malaria was increased in the rainy season which is October to April. The medium-high endemic area in Kokap I was Kalirejo village, while Hargomulyo and Hargorejo village was a low-moderate endemic area.

\section{Acknowledgments}

We would like to thank Kulon Progo Government for its permission and also for the head of Kokap I primary health center and his staff who helped to complete this research.

\section{References}

1. Getachew G, Tsige K: Severe Malaria Associated with Plasmodium falciparum and $P$. vivax among Children in Pawe Hospital, Northwest Ethiopia 2006, Malar. Res. Treat. 2016;1-7

2. WHO: World malaria report 2018. Luxembourg. 2018.

3. Kemenkes RI: Situasi terkini perkembangan program pengendalian malaria di Indonesia tahun 2018. Jakarta 2018.

4. Dinkes: Profil Kesehatan Provinsi DIY. Jakarta 2018.

5. Minoo M, Narges K, Bahram B, et al. : The Relation Between Climatic Factors and Malaria Incidence in Sistan and Baluchestan, Iran . Clim. Chang. 2019; 1-10.

6. Takayoshi I, Swadhin KB, Yushi M, et al. : Seasonally lagged effects of climatic factors on malaria incidence in South Africa. Nature. 2017; 7: 1-9.

7. Dinkes: Profil kesehatan Kabupaten Kulon Progo tahun 2015 (Data 2014). Yogyakarta. 2015.

8. BPS: Keadaan iklim rata-rata. DIY. Yogyakarta. 2018.

9. Nannim N, Crispinus MDA, Dakul, et al.: Prevalence of Human Malaria Infection and its Transmission Pattern in the Highlands and Lowlands of Plateau State, Nigeria. Indian J. Sci. Technol. 2017; 10: 1-9.

10. Rajini K, Geetanjali D, Abdullah AA: Malaria trend and effect of rainfall and temperature within Regions 7 and 8, Guyana. Int. J. Mos. 2017; 4: 48-55.

11. Cui G, Lin Y, Chun-Quan O, et al. : Malaria incidence from $2005-2013$ and its associations with meteorological factors in 2015. Malar. J.2015;14: 1-12.

12. Precious ADM, Godfred F, Leonard KA, et al. : Diversity in breeding sites and distribution of Anopheles mosquitoes in selected urban areas of southern Ghana. Parasit. Vectors. 2017: 10: 1-15.

13. Heny A, Subagyo Y, Etik AR, et al. : Submicroscopic malaria cases play role in local transmission in Trenggalek district, East Java Province, Indonesia. Malar. J. 2018; 2: 1-6. 
14. Kemenkes: Hasil Utama Riskesdas 2018. Jakarta. 2018.

15. Yibelta A, Abeba M, Abebaw B, et al. : Prevalence of malaria and associated risk factors among asymptomatic migrant laborers in West Armachiho District, Northwest Ethiopia. Res. Rep. Trop. Med. 2018; 9: 95-101.

16. Claudia S, Asik S, J. Kevin B: Epidemiology of Plasmodium vivax in Indonesia. Am. J. Trop. Med. Hyg. 2016; 95: 121-132.

17. Jontari $\mathrm{H}$ : Prevalence of asymptomatic submicroscopic malaria in eastern Indonesia : a cross sectional survey and spatial analysis. Lancet Glob. Heal. 2017;5 S13.

18. Collince JO, Daniel O, Lucy $\mathrm{K}$, et al. : Perennial transmission of malaria in the low altitude areas of Baringo County, Kenya. Malar. J. 201716 1-8.

19. Yousry H, Khadiga I, Khalaf A, et al. : Malaria Prevalence in a Low Transmission Area, Jazan District of Southwestern Saudi Arabia. Korean J. Parasitol. 2019; 57: 233-242.
20. Eduard R, Juan JC, Roberson R, et al. : Predominance of asymptomatic and sub- microscopic infections characterizes the Plasmodium gametocyte reservoir in the Peruvian Amazon. PLoS Negl. Trop. Dis. 2017 ; 111 18.

21. Elsa HM, AnisF, Mubarika DFN, et al. : Early malaria resurgence in pre-elimination areas in Kokap Subdistrict, Kulon Progo, Indonesia. Malar. J. 2014; 13: $1-15$.

22. Elsa HM, Anis F, Sulistyawati, et al.: Change of strategy is required for malaria elimination : a case study in Purworejo District, Central Java Province, Indonesia. Malar. J. 2015; 14: 1-14. 